\title{
Batik Patterns in the South of Thailand
}

\author{
Worasuda Khwansuwan \\ Faculty of Architecture, Rajamangala University of Technology Srivijaya, Songkhla, Thailand \\ Email:worasuda.k@rmutsv.ac.th
}

Received Date:13 June 2021

Accepted Date: 20 June 2021

Available Online: 30 August 2021

\begin{abstract}
"Batik" or "Pateh" is an important cloth in the south of Thailand. Its unique features such as pattern, colour, and production process make Batik different from other cloth in the other part of Thailand. Traditionally, Batik was originated in Indonesia and India where people used paraffin wax as a dye-resist paint. It was also reported that other Asian countries such as Japan and India made Batik fabric in their country. In Thailand, local people in the south made their clothes from Batik fabric and wore them in daily life or during special social events. They designed pattern and applied wax-resist dyeing by hand or blocks on the fabric to create colourful and creative designs. Batik is a cultural identity of the south of Thailand. The study found that the process of creating pattern and colour for Batik was used a long time ago. In the past, artisans primarily employed wooden molds or blocks and wax to create patterns. Through the accumulation of knowledge and experience over time, the development of metal blocks makes Batik's patterns more delicate and vivid. In addition, the research aimed to study about Batik pattern in the southern provinces of Thailand. It can be said that Batik is a uniquely beautiful fabric that should be collected as a national heritage and for the future study of this fabric. The study of Batik pattern in the south revealed that former patterns simply used basic geometric shapes such as lines, squares, and circles. Then, these patterns have been developed by integrating rhythms and spaces to create more distinctive and delicate designs. Moreover, the patterns of Batik in the south were inspired by nature, religious beliefs, and ways of life. Warm tone colours such as red, brown, yellow and cool tone colours such as blue and green were employed. It was also found that the materials used in the past were primarily from plants and nature. Nowadays, artificial colors are also used because they allow vivid and durable effects.
\end{abstract}

Keywords: Batik patterns, south of Thailand 


\section{INTRODUCTION}

In Asia, India was the very first country who produced Batik from cotton. Due to bad weather conditions at that time, it was difficult for people to keep all Batik patterns remained the same. Therefore, many patterns became faded away over time. The remaining patterns during that time simply portrayed the everyday life of the Indians. Later, when Batik was introduced into Indonesia, it became very popular, especially among ladies in the royal families. It was a marker of different classes and social status among people. Because of its great popularity, ordinary people started to make their Batik and it became Indonesian national costume.

In Thailand, Batik was initially made in the south. It started from in-house production where people adopted the techniques of using colors and patterns originally developed in Malaysia and Indonesia such as flora-fauna patterns. The new patterns were then developed as the people started to incorporate their identities and beliefs into their work. This beautiful work is considered important craftsmanship in the south of Thailand (Thongprayoon, 2003) and it, therefore, deserves more attention. This paper aimed to present the study of the artistic patterns of Batik, especially those in the south. In what follows, I provide more details about the development of Batik patterns in the south of Thailand.

\section{The development of Batik patterns}

The key characteristic of Batik is its patterns. It is found that Batik in the south of Thailand is influenced by the patterns of flora and fauna that originated in Indonesia and Malaysia. The most popular ones, the flora pattern, are the chrysanthemum pattern and the national flower of Malaysia. This includes geometric patterns and Islamic patterns. Generally, there are two main types of Batik patterns in the south, namely geometric and natural patterns as presented in the Figures below.
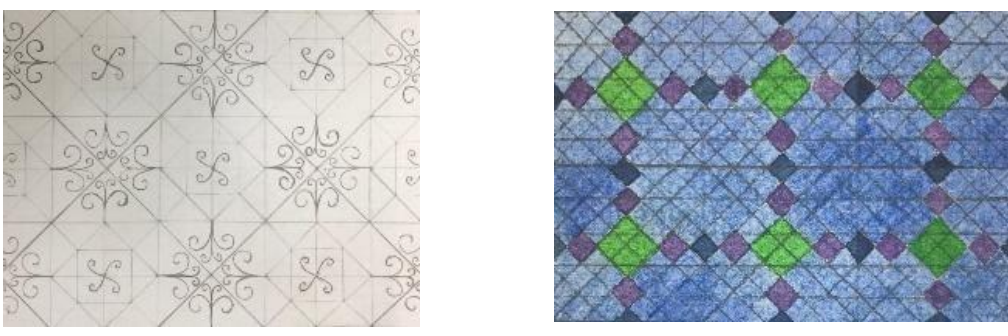

Figures 1-2. Geometric pattern

Source: Progress report research of Innovative 3D printing block for adding value of Batik fabric in the Southern Provinces. (Worasuda, 2020)
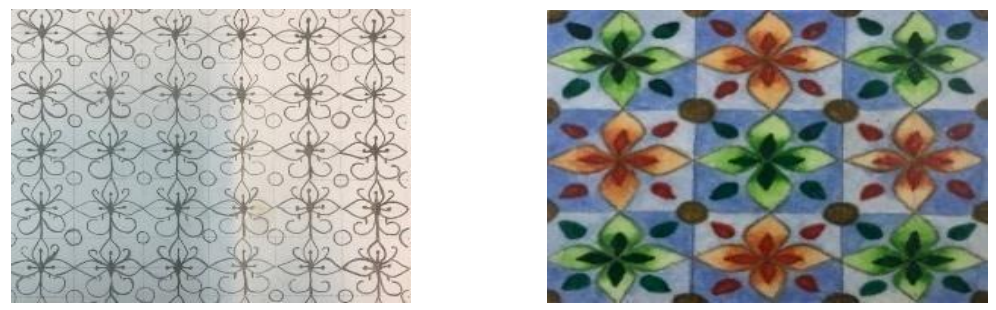

Figures 3-4. Natural pattern

Source: Progress report of Innovative 3D printing block for adding value of Batik fabric in the Southern Provinces Research (Worasuda, 2020) 
Batik patterns in Thailand have been evolved. Initially, the design was simple with the use of simple forms of geometric shapes such as straight lines as shown in Figures 5-8.
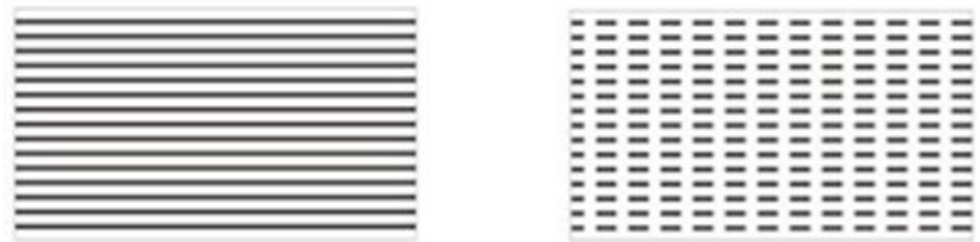

Figures 5-6. Patterns from geometric shapes: straight lines Source: The creative patterns to value of batik in South of Thailand (Worasuda, 2018)
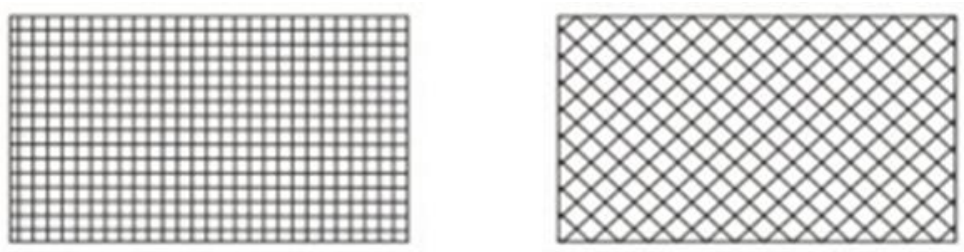

Figures 7-8. Patterns from line intersection

Source: The creative patterns to value of batik in South of Thailand (Worasuda, 2018)

Later, the pattern became more complex when designers combined different patterns and created more tactics and stories. As a result, there were more variety of distinctive and interesting patterns. They also used simple forms such as lines, curves, and dots to create the design. For example, the application of dots, lines, and nature lines (Figure 9), free lines (Figure 10), and an object from nature (Figure 11).

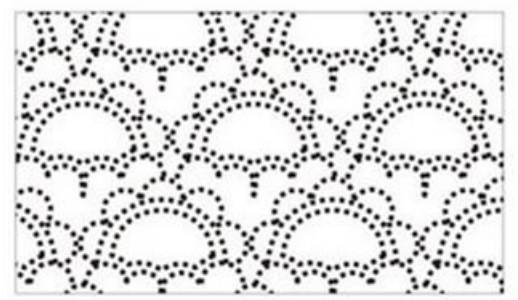

Figure 9. Patterns from the application of dots

Source: The creative patterns to value of batik in South of Thailand (Worasuda, 2018)

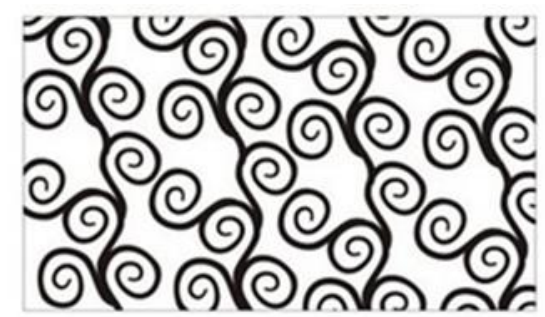

Figure 10. Patterns from the application of free line Source: The creative patterns to value of batik in South of Thailand (Worasuda, 2018) 


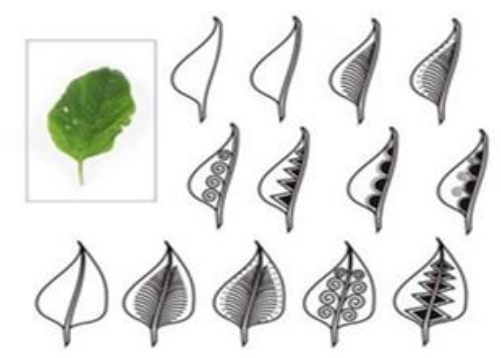

Figure 11. Patterns from the application of nature

Source: The creative patterns to value of batik in South of Thailand (Worasuda, 2018)

\section{The design of Batik patterns}

During the process of making patterns, the designers must follow the two principles of design and decoration. That is, the design should be most appropriate for functioning and adorning purposes. As the design and decoration complement each other, it is the designers' job to integrate these elements effectively. This section presents the application of four elements in the designs of Batik patterns namely, real-world objects; geometric shapes and forms; thoughts or ideas, and abstract concepts.

\section{Real-world objects}

In this pattern, the designers used objects in the real world together with their imagination. For example, the following graphic design of roses consists of structural lines and petal lines.
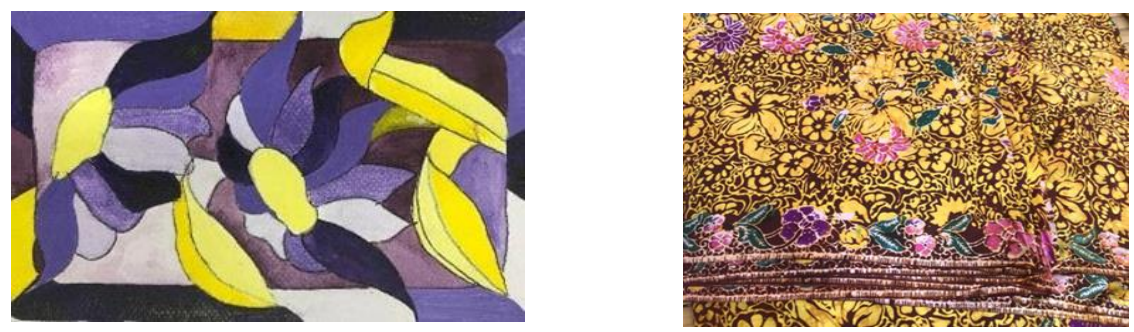

Figures 12-13. Patterns influenced by real-world objects

Source: Progress report of Innovative 3D printing block for adding value of Batik fabric in the Southern Provinces Research (Worasuda, 2020)

2. Geometric shapes and forms

This design is motivated by geometric forms and shapes such as circles, ovals, and squares as shown below.
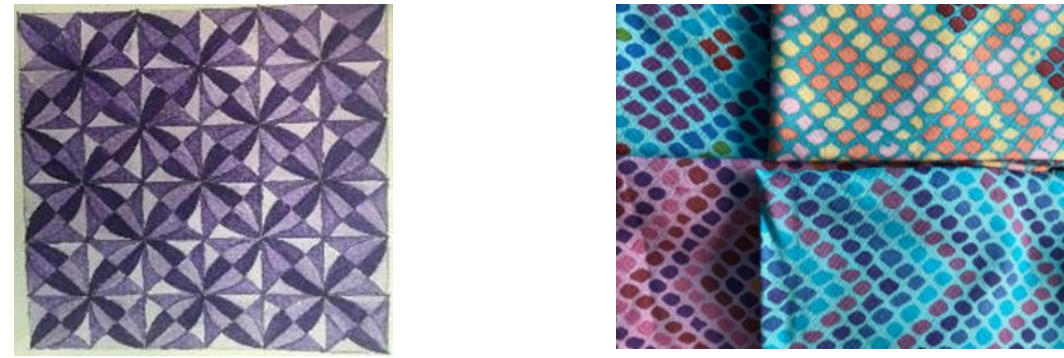

Figures 14-15. Patterns from geometric shapes

Source: Progress report of Innovative 3D printing block for adding value of Batik fabric in the Southern Provinces Research (Worasuda, 2020) 


\section{Thoughts or ideas}

This design is influenced by concepts, imagination, environment, and beliefs.
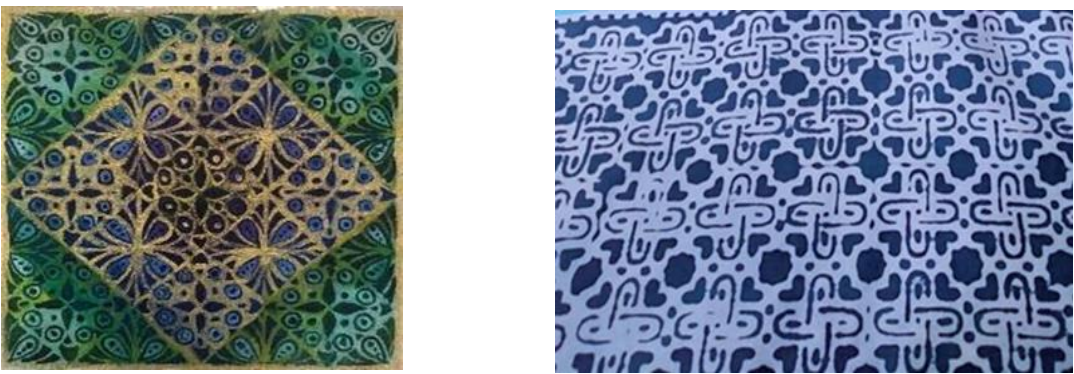

Figures 16-17. Patterns from thoughts or ideas

Source: Progress report of Innovative 3D printing block for adding value of Batik fabric in the Southern Provinces Research (Worasuda, 2020)

\section{Abstract concepts}

This design is inspired by abstract concepts or feeling such as confusion or simplicity.
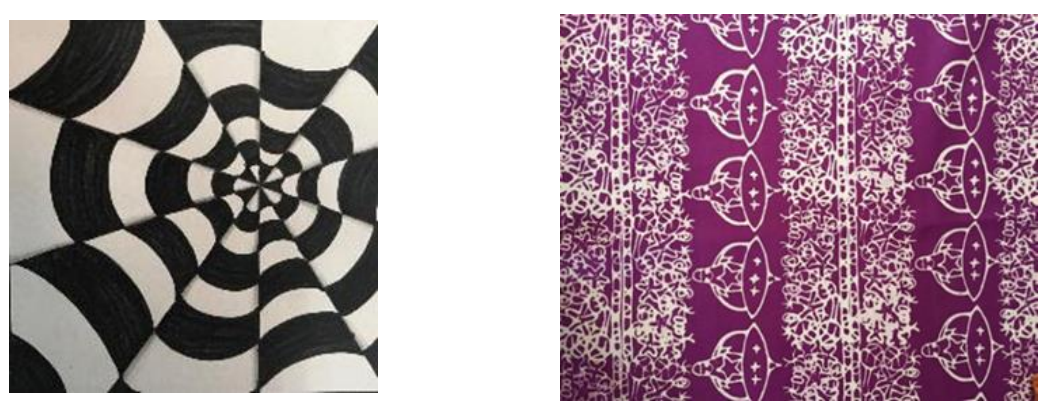

Figures 18-19. Patterns from abstract concepts

Source: Progress report of Innovative 3D printing block for adding value of Batik fabric in the Southern Provinces Research (Worasuda, 2020

\section{Batik patterns production process}

Apart from the patterns that make Batik unique, the production procedures are also specific to Batik. As mentioned earlier, the Batik patterns in the south are unique because they are different from the other fabric in other regions. These patterns are created by specific techniques. That is, parts of the fabric are blocked from the colors by using melted wax or candle. In the old-time, boiled flour, mud, or clay were used to block the color from accessing the fabric and bleaching the color. Before presenting the methods of painting Batik, it is necessary to mention two kinds of blocks: metal blocks and wooden blocks. 


\section{Metal block}

This type of block gives very fine lines. The design of this kind of block can be classified into 3 types: the line block, covered block, and background coloring block.
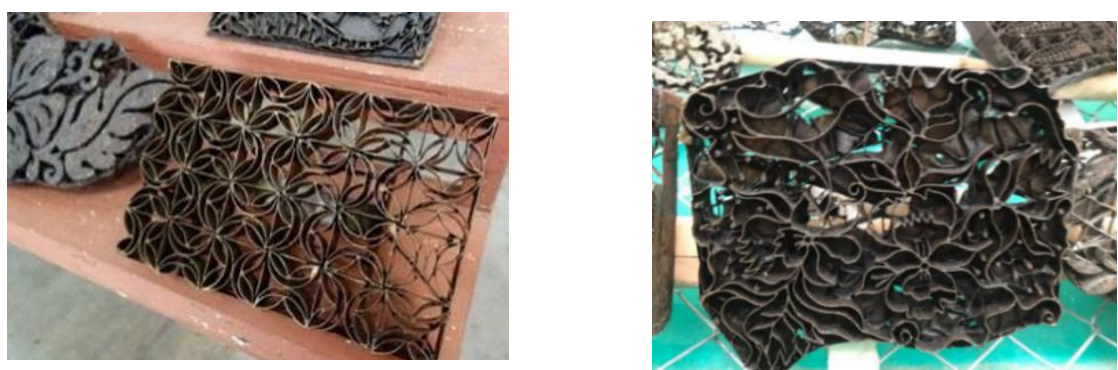

Figures 20-21. Metal blocks

Source: Progress report of Innovative 3D printing block for adding value of Batik fabric in the Southern Provinces Research (Worasuda, 2020)

2. Wooden blocks

This type of block is made from wooden board. However, it does not give detailed patterns. It simply gives thick lines in white color, which results from the candle- covered block on the color-dyed background.
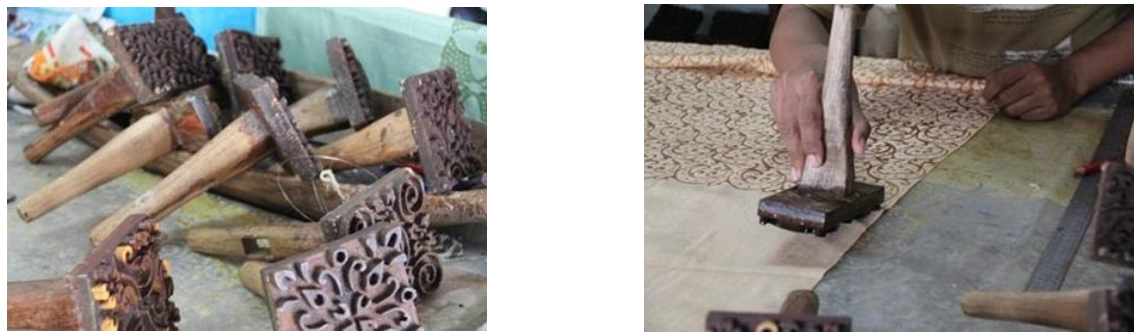

Figures 22-23. Wooden blocks

Source: Progress report of Innovative 3D printing block for adding value of Batik fabric in the Southern Provinces Research (Worasuda, 2020)

According to the studies of Batik in the south of Thailand, there are six methods of painting Batik.

1. Block-printed Batik: Blocks made from metal, wood, or ropes are dipped into the hot melted candles. Then, they were immediately stamped on the fabric. The fabric is repeatedly dyed 3 to 4 times in cold dyeing.

2. Candle-drawing and Dyeing Batik: The designer draws on the fabric using a candle to block the color. Canting is also used to draw lines and patterns. The fabric is dyed 1 to 2 times. As many colors can be used, the first color is covered by a candle and another color is used after that. The methods of redrawing and re-dyeing can be used. Crackling can be made by knife-craping and crushing the candlecovered fabric and put it into cold water before drying and dyeing.

3. Hand-drawing and painting Batik: The designer uses a candle to draw lines and patterns and paints the whole cloth.

4. Candle-Blocked and Bleached Batik

5. Painted Batik: Traditionally, wax is mixed with candle and turpentine to paint on the fabric.

6. Mixed-method Batik

Another important and advanced technique in the production of the patterns involves handwriting (Batik Tulis) by using canting. (a tool used for drawing that looks like a pen). There is a spout at the end of the cone. The hot candle is drawn through canting on the fabric. The designer needs to draw the patterns while https://melaka.uitm.edu.my/ijad/index.php | eISSN | 29 
the candle is still warm. The part that is not covered by the candle will take up the dye. Then, the fabric is put into boiling water to remove the candle.

\section{Batik pattern colors}

In terms of color, the early form of Batik used only blue and white. Until the discovery of new colors such as red, brown, yellow from plants and nature in the 17th century, colors on Batik became various. Nowadays, Batik dye uses synthetic colors from chemicals because they allow brightness and long-lasting effects. The theory of color is important for designers. One way to choose a color palette is to look at the tone of the fabrics. In general, warm colors are red, orange, and yellow, while cool colors are blue, purple, and green. In quilting fabrics, warm colors can be energetic and cool colors tend to be calming. Therefore, the use of one over the other will probably evoke a certain feeling to the fabric. Mixing warm and cool colors is a great way to choose a color palette. The best way to make warm tone color and cool color is by having 80 percent: 20 percent or 70 percent: 30 percent of warm or cool color. For instance, the designer may choose one warm, one cool, and one neutral color.
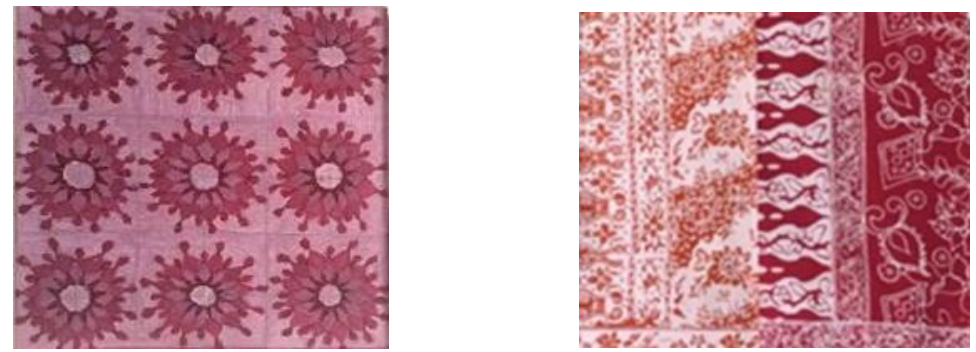

Figures 24-25. Warm tone colors

Source: Progress report of Innovative 3D printing block for adding value of Batik fabric in the Southern Provinces Research (Worasuda, 2020)
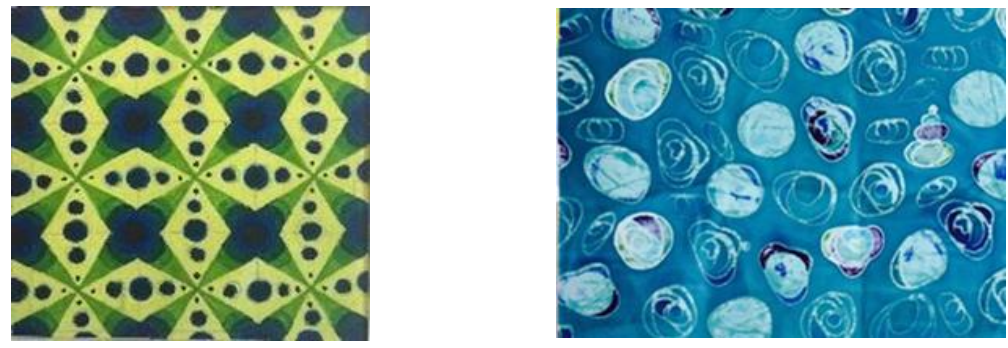

Figures 26-27. Cool tone colors

Source: Progress report of Innovative 3D printing block for adding value of Batik fabric in the Southern Provinces Research (Worasuda, 2020) 

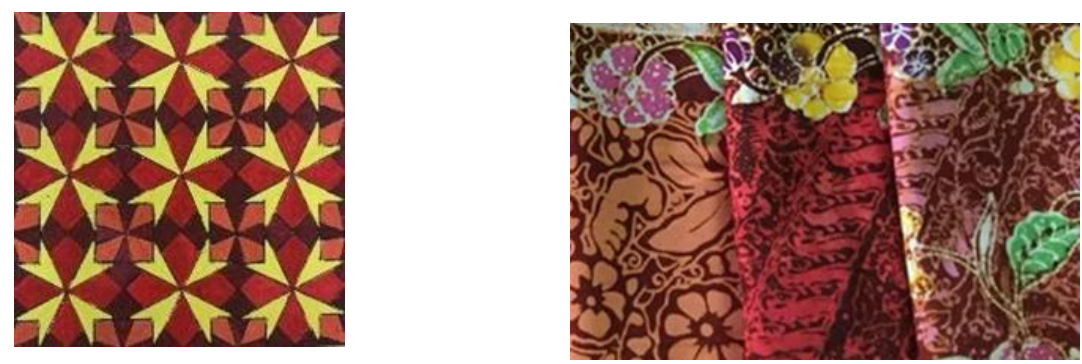

Figures 28-29. Warm tone color $80 \%$ and cool tone color $20 \%$

Source: Progress report of Innovative 3D printing block for adding value of Batik fabric in the Southern Provinces Research (Worasuda, 2020)
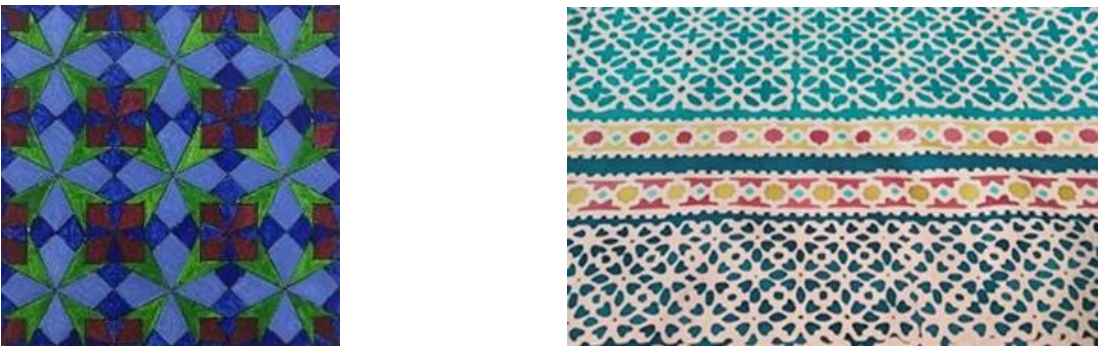

Figures 30-31. Cool tone color $80 \%$ Warm tone color $20 \%$

Source: Progress report of Innovative 3D printing block for adding value of Batik fabric in the Southern Provinces Research (Worasuda, 2020)

All in all, the study of Batik patterns in the south of Thailand found four main types of patterns using wooden and metal blocks. They were:

1) a pattern using disconnected geometric forms;

2) a pattern using the repetition of geometric forms;

3) a pattern inspired by (disconnecting) forms in nature

4) a pattern inspired by (repeating) forms in nature

Regarding the use of colours, the application of pastel colours and tone colours becomes common in modern pattern design.

\section{CONCLUSION}

In conclusion, Batik in the southern provinces of Thailand is a uniquely beautiful fabric. Should be collected as a national heritage and for the future study of this fabric in term of patterns, color, and production. In addition, Batik in the south of Thailand nowadays has become more famous because of its attractive beauty and uniqueness. Modern Batik is more colorful and has a more useful function. It can be adapted to make other products such as handkerchiefs, scarves, hijabs, coats, etc. Therefore, the designers must continue developing more patterns and study further on effective techniques and methods of making distinctive Batik designs. With the creative use of different forms, patterns, and colors, batik makers will be able to create Batik patterns, designs, and products that are distinctively beautiful, useful, and meet consumers' needs. 


\section{References}

Graves Maitland. (1951). The Art of Colour and Design. New York: McGrand-Hill Book Company.

Juhri Selamet. (2018). Indonesian Batik Translation: A Case Study. Journal. , University of Colorado Boulder, USA

Linda S.Mcintosh. (2012). Art of Southeast Asian Textile; the Textile and Gibbins Collection. Serindia Publications, Chicago.

Lucie - Smith, Edwrd. (1983). A History of Industrial Design. New York: Ven Nostrand Reinhold Company Inc.

Maria Wronska. (2018). Batik of Java: Global Inspiration.Indonesia.

Noor Azlina Yunus. (2012). Malaysian Batik: Reinventing a Tradition. Malaysia.

National Geographic Traveller Indonesia. (2009). Vol 1, No 6, Jakarta, Indonesia.

Nuntha Rochanaudomsart. (1992). How to create Batik., OdeanStore, Bangkok.

Rudolf Smend. (2000). Batik Tradition Textile of Indonisia. Hardcover, Jacketed.

Sri Lankan Batik Textiles. (2014). Lakpura Travels.

Suppaluke Thongprayoon. (2002).To study patterns of Batik in South of Thailand., Research, Ratchabat University Songkhla, Thailand.

Thawatchai Thumthong. (2002). Art of Batik Pattern paint, OdeanStore, Bangkok.

Worasuda Khwansuwan.(2018).The creative patterns to value of batik in South of Thailand.[Proceeding].The $3^{\text {rd }}$ National and International Conference on Weaving ASEAN Cultura Connection "ASEAN Art and Craft", Walailak University, Nakhon Si Thammarat, Thailand.

Worasuda Khwansuwan. (2020). Innovative 3D printing block for adding value of Batik fabric in the Southern Provinces (Progress report). Rajamangala University of Technology Srivijaya Songkhla, Thailand 